\title{
Prevalence of smoking in adults with chronic pain
}

Vwaire J. Orhurhu', Thomas P. Pittelkow ${ }^{2}$ and W. Michael Hooten ${ }^{3^{*}}$

\begin{abstract}
Introduction: Cigarette smoking is common among adults with chronic pain. The primary objective of this study was to determine the period prevalence of smoking in patients with chronic pain. A secondary objective was to determine the prevalence of smoking among patients with commonly occurring pain diagnoses including fibromyalgia, low back pain, and headache.

Methods: This population study included 5350 patients (1256 smokers, 4094 nonsmokers) admitted to the Mayo Comprehensive Pain Rehabilitation Center from January 1998 through December 2012. Smoking status was determined using a self-report questionnaire.

Results: During the 15 year study period, the overall prevalence of smoking was $23.5 \%$ (95 \% Cl 22.4 - 24.6). The prevalence of smoking in 2000, 2005, and 2010 was 24.2, 25.7, and $28.3 \%$ respectively. The overall prevalence of smoking in patients with fibromyalgia, low back pain, and headache was $25.2 \%$ (95\% Cl $22.8-28.3$ ), $22.8 \%$ (95\% Cl 21.3 - 25.9), and $21.2 \%$ (95\% Cl 17.9 - 24.7), respectively. In a multiple variable logistic model adjusted for age and sex, opioid use was significantly associated with status as a current smoker.

Conclusion: The prevalence of smoking in patients with chronic pain has not declined when compared to the general population. The higher prevalence of smoking was consistently observed in commonly occurring pain diagnoses including fibromyalgia, back pain, and headache. Further research is needed to identify the potential factors that contribute to the high prevalence of smoking in this patient population.
\end{abstract}

Keywords: Smoking, Chronic pain, Prevalence, Low back pain, Fibromyalgia, Chronic headache

\section{Introduction}

The single greatest preventable cause of death in the United States is cigarette smoking [7]. The health implications of smoking in chronic pain conditions remains complex, but several studies have shown positive associations $[4,11,20,26,28,31,41]$. For example, smokers report greater pain intensity and a greater number of painful sites compared to nonsmokers [19, 36]. In addition, smokers with chronic pain admitted to specialty pain treatment centers report greater levels of functional impairment compared to nonsmokers [10, 14, 38, 39].

The prevalence of smoking in the general population has declined over the past decade, but is still estimated at $19.3 \%$ [2]. However, the rate of smoking in individuals with chronic pain appears to remain higher compared to

\footnotetext{
* Correspondence: hooten.william@mayo.edu

${ }^{3}$ Department of Anesthesiology, Division of Pain Medicine, Mayo Clinic College of Medicine, 200 First Street SW, Rochester, MN 55905, USA
}

Full list of author information is available at the end of the article the general population $[3,9,26,31]$. Therefore, the primary aim of this study was to determine the period prevalence of smoking in patients with chronic pain admitted to an interdisciplinary pain treatment center from January, 1998 through December, 2012. A secondary aim was to determine the prevalence of smoking in patients with commonly occurring pain diagnoses including fibromyalgia, chronic low back pain, and headache.

\section{Methods}

\section{Study participants}

This study was approved by the Mayo Foundation Institutional Review Board, and all patients provided prior written consent for use of their medical records for research purposes. Inclusion criteria included admission to the Mayo Comprehensive Pain Rehabilitation Center from January, 1998 through December, 2012, age $\geq 18$, and pain duration $\geq 6$-months. Exclusion criteria included use of other forms of tobacco besides cigarettes 
including oral tobacco, cigars, or pipe. Patients who did not indicate smoking status were excluded from study participation. During this time period, 5617 patients with chronic pain were admitted to the pain treatment center; 267 patients (4.9\%) were excluded from study participation due to use of other forms of tobacco and missing data. The population study was comprised of 5350 individuals (1256 smokers, 4094 nonsmokers).

\section{Study setting}

The study setting was a 3-week, outpatient pain rehabilitation program. Descriptions of this treatment setting have been previously reported $[14,17,18]$. In brief, the primary goal of treatment is restoration of physical and emotional functioning. A cognitive-behavioral model serves as the basis for treatment. Patients referred for this type of therapy have generally received medical and surgical care for chronic pain, and experienced incomplete symptomatic relief from conventional treatments including pharmacologic trials, physical therapy, interventional pain procedures, and surgery. Multidisciplinary pain treatment differs from independently prescribed outpatient physical therapy, occupational therapy, and cognitive-behavioral therapy in that patients are involved in all these treatment modalities concurrently on a daily basis throughout the treatment period. Admissions to the rehabilitation program occur on a revolving basis and patients attend $8 \mathrm{~h}$ daily for 15 consecutive working days. During the course of treatment, patients are involved in daily physical reconditioning, biofeedback and relaxation training, stress management, chemical health education, activity moderation, and elimination of pain behaviors. Patients are also involved in daily cognitivebehavioral group educational sessions where the aforementioned aspects of pain rehabilitation are addressed.

\section{Smoking status}

Smoking status was assessed upon admission to the pain treatment center using a self-report questionnaire as previously described $[14,17]$. Incomplete data were available to categorize never smokers and former smokers into separate groups; therefore, patients identified as either never or former smokers were categorized as nonsmokers. Patients who reported smoking cigarettes upon admission were categorized as smokers.

\section{Pain diagnosis and pain duration}

Upon admission, the primary anatomical site of chronic pain or underlying pain condition (i.e., fibromyalgia) was identified and used as the primary pain diagnosis. This approach for identifying the primary pain diagnosis has been extensively used in our pain treatment program $[14,17,18]$. In addition, the duration of chronic pain was assessed upon admission by self-report and review of the medical record. This method of assessing pain duration has been used extensively in our pain treatment program $[14,17,18]$.

\section{Statistical analyses}

The summary statistics for continuous data were reported as an average ( \pm standard deviation; SD), and categorical data were reported as a number (percent). The demographics and clinical characteristics (age, sex, ethnicity, place of residence, pain diagnosis, pain duration) were summarized for smokers and nonsmokers. The comparison between smokers and nonsmokers was made using chi-squared test for categorical variables and univariate analysis of variance for continuous variables. The proportion of smokers and nonsmokers in the year 2000 was compared to the proportion of smokers and nonsmokers in 2005 and 2010 using chisquared tests. Multiple variable logistic regression analysis was used to assess the potential associations between smoking status (dependent variable) and opioid use (independent variable) in a model adjusted for age and sex. Similarly, multiple variable logistic regression analysis was used to assess the potential associations between smoking status and ethnicity in a model adjusted for age and sex. For purposes of this particular analysis, the Hispanic and African American groups were combined and the "undisclosed" ethnic group was omitted. Two-sided tests were used in all analyses, and the level of significance for all statistical tests was set at $P<0.05$. All analyses were completed using JMP version 9.0.1 (SAS Institute, Cary, NC).

\section{Results}

\section{Demographic and clinical characteristics}

The population study $(n=5350)$ was comprised of 1256 smokers and 4094 nonsmokers. The total number of women was 3812 and the total number of men was 1538 (Table 1). The majority of patients were married Caucasian women living outside the state of Minnesota. A greater proportion of nonsmokers were currently employed; otherwise, no significant differences in demographic or clinical characteristics based on smoking status were identified.

\section{Prevalence of smoking in adults with chronic pain}

During the 15 year study period, the overall prevalence of smoking was $23.5 \%$ (95 \% CI $22.4-24.6)$. The yearly trend for smoking prevalence ranged from 19.9 to 28.3 \% (95 \% CI 24.2 - 32.7) (Fig. 1). During the 15 year study period, the prevalence of smoking among Hispanics and African Americans was 26.8 \% (95 \% CI 15.2 - 38.4) and 19.6 (95 \% CI 11.7 - 27.5), respectively. No significant differences in smoking prevalence were observed when smoking status was based on sex and stratified by age (Table 2). Within 5-year intervals starting in 2000, the 
Table 1 Baseline demographic and clinical characteristics of smokers and nonsmokers

\begin{tabular}{|c|c|c|c|}
\hline Characteristics & $\begin{array}{l}\text { Smokers } \\
(n=1256)\end{array}$ & $\begin{array}{l}\text { Nonsmokers } \\
(n=4094)\end{array}$ & $P$ value* \\
\hline Age (mean $\pm S D)$ & $46.3 \pm 13.9$ & $45.9 \pm 13.5$ & 0.315 \\
\hline $\operatorname{Sex}(n, \%)$ & & & 0.256 \\
\hline Male & $377(30)$ & $1161(28)$ & \\
\hline Female & $879(70)$ & $2933(72)$ & \\
\hline Ethnicity & & & 0.625 \\
\hline Caucasian & $1072(85.4)$ & $3517(86.0)$ & \\
\hline Hispanic & $15(1.2)$ & $41(1.0)$ & \\
\hline African American & $19(1.5)$ & $78(1.9)$ & \\
\hline Undisclosed & $150(11.9)$ & $458(11.1)$ & \\
\hline Marital status & & & 0.743 \\
\hline Married & 786 (63.6) & $2546(63)$ & \\
\hline Single/Divorce & $449(36.4)$ & $1487(39)$ & \\
\hline Residence & & & 0.705 \\
\hline Minnesota & $503(40.1)$ & $1663(40.7)$ & \\
\hline Non Minnesota & $752(59.9)$ & $2425(59.3)$ & \\
\hline Years of education & $14.9 \pm 8.4$ & $14.5 \pm 3.0$ & 0.918 \\
\hline Currently employed & $196(15.6)$ & $743(18.1)$ & 0.042 \\
\hline Pain duration, years & $9.7 \pm 10.2$ & $9.8 \pm 10.6$ & 0.763 \\
\hline Primary pain site & & & 0.738 \\
\hline Fibromyalgia & $239(19.0)$ & $700(17.1)$ & \\
\hline Low back & $317(25.2)$ & $1030(25.2)$ & \\
\hline Headache & $117(9.3)$ & $438(10.7)$ & \\
\hline Generalized & $132(10.5)$ & $439(10.7)$ & \\
\hline Abdominal & $97(7.7)$ & $315(7.7)$ & \\
\hline Neck & $92(7.3)$ & $269(6.6)$ & \\
\hline Lower extremity & $92(7.3)$ & $326(8.0)$ & \\
\hline Face & $30(2.4)$ & $122(3.0)$ & \\
\hline Upper extremity & $63(5.0)$ & $213(5.2)$ & \\
\hline Other & $77(6.2)$ & $242(5.9)$ & \\
\hline
\end{tabular}

${ }^{*}$ Chi-square for categorical variable, univariate analysis of variance for continuous variable

prevalence of smoking fluctuated but a trend towards increased rates was observed starting in the year 2000 (24.2\%) and extending through 2005 (25.7 \%) and 2010 (28.3 \%) (Fig. 1). However, no significant difference was observed in the proportion of patients who smoked in the year 2000 compared to 2005 (P>.1). Similarly, no significant difference was observed in the proportion of patients who smoked in the year 2000 compared to $2010(P>.1)$.

\section{Prevalence of smoking in diagnostic subgroups}

During the 15 year study period, the overall prevalence of smoking in patients with fibromyalgia, low back pain, and headache was $25.2 \%$ (95 \% CI $22.8-28.3$ ), $22.8 \%$ (95 \% CI 21.3 - 25.9), and $21.2 \%$ (95\% CI 17.9 - 24.7), respectively.

\section{Associations between smoking status, opioid use, and ethnicity}

In a logistic regression model adjusted for age and sex, opioid use was significantly associated with status as a current smoker (odds ratio $=1.4,95 \%$ CI 1.2 to 1.6, $P=<.001$ ). In a logistic regression model adjusted for age and sex, no significant association was found between ethnicity and smoking status (odds ratio $=1.0$, $95 \%$ CI .99 - 1.1, $P=.704)$.

\section{Discussion}

The period prevalence of smoking in this group of patients with chronic pain admitted to an outpatient pain rehabilitation program over a 15 -year period was $23.5 \%$. No significant differences in the prevalence of smoking was observed among subgroups of patients diagnosed with fibromyalgia, low back pain, or headache. However, a significant association was observed between opioid use and status as a current smoker in a multiple variable regression model adjusted for age and sex.

The prevalence of smoking in the general population in 2000,2005 , and 2010 was $23.3,20.9$, and $19.3 \%$, respectively $[2,6]$. For the same time periods, the prevalence of smoking in our sample of adults with chronic pain was 24.2, 25.7, and $28.3 \%$, respectively. Although fluctuations in the prevalence of smoking occurred during the time period of the study, the increasing trend observed in our study compared to the decreasing trend in the general population could be due, in part, to clinical characteristics unique to patients with chronic pain including concomitant use of opioids. In the current study, opioid use was significantly associated with status as a current smoker. This is an important because we have previously reported that smokers were more likely to use opioids compared to former and never smokers [15, 16]. In addition, smokers were more likely to consume greater quantities of opioids due, in part, to use of greater dosages by men [15]. The association between smoking and opioid dose occurred independent of key demographic and clinical characteristics including age, marital status, years of education, employment status, pain duration, and pain severity $[13,16]$. Previous studies also suggest that it may be more difficult for smokers receiving long-term opioid therapy to quit smoking [14, 17, 18]. These clinical observations are supported by preclinical studies that suggest the antinociceptive effects of nicotine and morphine are linked, and that morphine-related antinociception is influenced by activation of supraspinal nicotinic acetylcholine receptors [30, 33, 34]. 


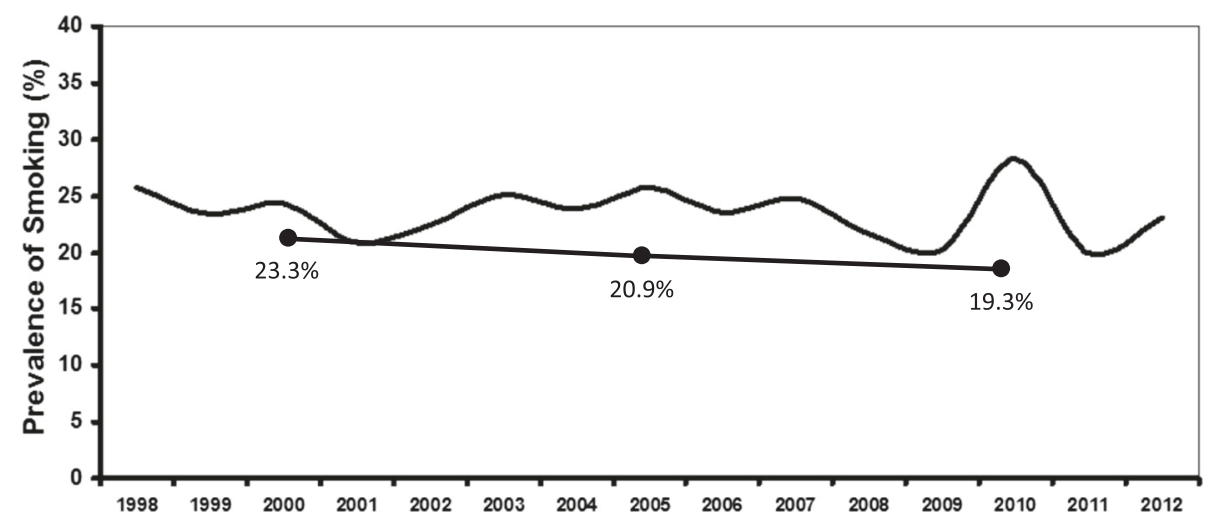

Fig. 1 The curved line represents the prevalence of smoking in patients with chronic pain. The straight line indicates the prevalence of smoking in the general population for the years 2000, 2005, and 2010

Although no significant association was found between ethnicity and smoking status in our study, the prevalence of smoking among Hispanic and African Americans was mixed when compared to the general population. For example, in the general population the prevalence of smoking among Hispanics in 2000, 2005 and 2010 was 18.6, 16.2 , and $12.5 \%$, respectively [6, 7]. During the 15 year time period of our study, the prevalence of smoking among Hispanic adults with chronic pain was $26.8 \%$ which was higher compared to the general population. Conversely, in the general population the prevalence of smoking among African Americans in 2000, 2005, and 2010 was $23.2,21.5,18.1 \%$, respectively $[6,7]$. During the 15 year time period of our study, the prevalence of smoking among African Americans was $19.6 \%$. In previous studies from our pain treatment center, the prevalence of smoking among a small group of Hispanic $(n=26)$ and African American $(n=22)$ adults with chronic pain was 11.5 and $31.8 \%$, respectively $[13,15,16]$. These mixed data derived from small samples suggest that larger ongoing studies are needed to further investigate the prevalence of smoking among Hispanic and African Americans with chronic pain.

The three most commonly occurring pain diagnoses in our study sample were fibromyalgia, low back pain, and chronic headache, and the observed prevalence of smoking among patients in these diagnostic groups extends and confirms the observations of previous studies. The prevalence of smoking among patients with fibromyalgia during the 15 year study period was $25.2 \%$. In previous studies, the prevalence of smoking among patients with fibromyalgia ranged from 9.8 to $25.5 \%$ [23, 25, $27,39,40]$. Greater impairments in pain-related functioning were observed among patients with fibromyalgia who smoke [39]. Patients in our study were admitted to a 3 -week outpatient pain rehabilitation program that specifically treated individuals with pain-related impairments in functioning which could partly explain the high prevalence of smoking in our patients with fibromyalgia. Smoking is widely recognized to be a risk factor for chronic low back pain [21, 32]. In previous studies, the prevalence of smoking in this patient population ranged from $16 \%$ to as high as $40 \%[5,22,24,36]$. The prevalence of smoking during the 15 year study period in our group of patients with low back pain $(22.8 \%)$ was consistent with these previously reported observations. Finally, the prevalence of smoking among patients with chronic headache, including migraine, ranged from $3 \%$ to as high as 25 to $28 \%$ in previous studies $[1,8,29,35]$. During the 15 year study period, our observed prevalence of $21.2 \%$ was consistent with these previous reports, but direct comparisons are limited by

Table 2 Prevalence of smoking based on sex and stratified by age

\begin{tabular}{llll}
\hline Characteristics & $\begin{array}{l}\text { Prevalence }\left(95 \% \mathrm{Cl}{ }^{*}\right) \\
\text { Men }(n=1538)\end{array}$ & $\begin{array}{l}\text { Prevalence }(95 \% \mathrm{Cl}) \\
\text { Women }(n=3812)\end{array}$ & $\begin{array}{l}\text { Prevalence }(95 \% \mathrm{Cl}) \\
\text { Total }(n=5350)\end{array}$ \\
\hline $\begin{array}{l}\text { Overall } \\
\text { Age group (yrs) }\end{array}$ & $24.5(22.4-26.7)$ & $23.1(21.7-24.4)$ & $23.5(22.4-24.6)$ \\
$18-24$ & $22.2(14.0-33.1)$ & $26.2(20.9-32.3)$ & $25.2(20.8-30.2)$ \\
$25-44$ & $25.5(22.1-29.3)$ & $22.2(20.2-24.4)$ & $23.1(21.4-24.9)$ \\
$45-64$ & $23.2(20.2-26.5)$ & $22.8(20.9-25.0)$ & $23.0(21.3-24.7)$ \\
$\geq 65$ & $28.1(21.3-36.0)$ & $25.3(21.1-29.9)$ & $26.0(22.5-29.9)$ \\
\hline
\end{tabular}


the diagnostic heterogeneity that exists among our headache patients.

This study has limitations. First, the majority of study participants were Caucasian women residing in the United States, and all study participants were specifically referred for pain rehabilitation at a tertiary medical center. This is consistent with the referral pattern of our pain treatment program $[12,15]$, but it could limit the generalization of the study findings to other populations of adults with chronic pain. However, the clinical characteristics of patients admitted to the pain program were comparable to those of a random sample of community adults with chronic pain derived from the catchment area of our medical center [37]. Second, patients were assigned to 1 of 10 broadly defined diagnostic groups upon admission to the pain rehabilitation program, but the specific subtype of pain (e.g., neuropathic, nociceptive) was not assessed. This could have influenced the prevalence of smoking in the defined diagnostic subgroups. Third, never smokers and former smokers were categorized as nonsmokers. We have previously reported that significant differences exist between never and former smokers with chronic pain. More specifically, former smokers were older, reported longer pain duration, and were more likely to use daily prescription opioids compared never smokers $[13,15,16]$. The categorization of never and former smokers as nonsmokers could explain the absence of significant group differences in the baseline demographic and clinical characteristics between smokers and nonsmokers as reported herein. Fourth, the number of cigarettes smoked daily was not assessed. However, we have previously reported that smokers admitted to our pain treatment program consume 14 to 18 cigarettes daily [15-17].

In summary, the prevalence of smoking in patients with chronic pain has not declined when compared to the general population. The high prevalence of smoking was consistently observed in commonly occurring pain diagnoses including fibromyalgia, back pain, and headache. The high prevalence of smoking among patients with chronic pain could be related, in part, to unique factors that exist in this patient population including concurrent opioid use.

\section{Competing interests}

The authors declare that they have no competing interests.

\section{Authors' contributions}

VJO, TPT, and WMH designed the study. VJO and WMH performed the data analysis. VJO, TPT, and WMH wrote the manuscript. All authors critically revised the manuscript and approved the final form of the manuscript. All authors read and approved the final manuscript.

\section{Acknowledgements}

The research was conducted at the Mayo Pain Rehabilitation Center and the Translational Research Unit for Chronic and Acute Pain, Department of Anesthesiology, Mayo Clinic, Rochester, MN 55905, USA.

\section{Author details}

'Mayo Clinic College of Medicine, Rochester, MN 55905, USA. 'Department of Anesthesiology, Division of Pain Medicine, Mayo Graduate School of Medicine, Rochester, MN 55902, USA. ${ }^{3}$ Department of Anesthesiology, Division of Pain Medicine, Mayo Clinic College of Medicine, 200 First Street SW, Rochester, MN 55905, USA.

Received: 24 December 2014 Accepted: 8 July 2015

Published online: 17 July 2015

\section{References}

1. Aamodt AH, Stovner LJ, Hagen K, Brathen G, Zwart J. Headache prevalence related to smoking and alcohol use. The Head-HUNT Study. Eur J Neurol. 2006;13:1233-8.

2. Agaku IT, King BA, Dube SR. Current cigarette smoking among adults - United States, 2005-2012. MMWR Morb Mortal Wkly Rep. 2014;63:29-34.

3. Alkherayf F, Agbi C. Cigarette smoking and chronic low back pain in the adult population. Clin Invest Med. 2009;32:E360-7.

4. Andersson H, Ejlertsson G, Leden I. Widespread musculoskeletal chronic pain associated with smoking. An epidemiological study in a general rural population. Scand J Rehabil Med. 1998;30:185-91.

5. Bjorck-van Dijken C, Fjellman-Wiklund A, Hildingsson C. Low back pain, lifestyle factors and physical activity: a population based-study. J Rehabil Med. 2008:40:864-9.

6. Centers for Disease Control and Prevention (CDC). Cigarette smoking among adults-United States, 2000. MMWR Morb Mortal Wkly Rep. 2002;51:642-5.

7. Centers for Disease Control and Prevention (CDC). Vital signs: current cigarette smoking among adults aged $>/=18$ years - United States, 2005-2010. MMWR Morb Mortal Wkly Rep. 2011;60:1207-12.

8. Fernandez-de-Las-Penas C, Hernandez-Barrera V, Carrasco-Garrido P, Alonso-Blanco C, Palacios-Cena D, Jimenez-Sanchez S, et al.

Population-based study of migraine in Spanish adults: relation to socio-demographic factors, lifestyle and co-morbidity with other conditions. J Headache Pain. 2010;11:97-104.

9. Fishbain DA, Lewis JE, Bruns D, Meyer LJ, Gao J, Disorbio JM. The prevalence of smokers within chronic pain patients and highest pain levels versus comparison groups. Pain Med. 2012;14:403-16.

10. Goesling J, Brummett CM, Hassett AL. Cigarette smoking and pain: depressive symptoms mediate smoking-related pain symptoms. Pain. 2012;153:1749-54.

11. Hestbaek L, Leboeuf-Yde C, Kyvik KO. Are lifestyle-factors in adolescence predictors for adult low back pain? A cross-sectional and prospective study of young twins. BMC Musculoskelet Disord. 2006;7:27.

12. Hooten WM, Knight-Brown M, Townsend CO, Laures HJ. Clinical outcomes of multidisciplinary pain rehabilitation among african american compared with caucasian patients with chronic pain. Pain Med. 2012;13:1499-508.

13. Hooten WM, Shi Y, Gazelka HM, Warner DO. The effects of depression and smoking on pain severity and opioid use in patients with chronic pain. Pain. 2010;152:223-9.

14. Hooten WM, Townsend CO, Bruce BK, Schmidt JE, Kerkvliet JL, Patten CA, et al. Effects of smoking status on immediate treatment outcomes of multidisciplinary pain rehabilitation. Pain Med. 2009;10:347-55.

15. Hooten WM, Townsend CO, Bruce BK, Shi Y, Warner DO. Sex differences in characteristics of smokers with chronic pain undergoing multidisciplinary pain rehabilitation. Pain Med. 2009;10:1416-25.

16. Hooten WM, Townsend CO, Bruce BK, Warner DO. The effects of smoking status on opioid tapering among patients with chronic pain. Anesth Analg. 2009;108:308-15.

17. Hooten WM, Townsend CO, Hays JT, Ebnet KL, Gauvin TR, Gehin JM, et al. A cognitive behavioral smoking abstinence intervention for adults with chronic pain: a randomized controlled pilot trial. Addict Behav. 2013;39:593-9.

18. Hooten WM, Vickers KS, Shi Y, Ebnet KL, Townsend CO, Patten CA, et al. Smoking cessation and chronic pain: patient and pain medicine physician attitudes. Pain Pract. 2011;11:552-63.

19. John U, Hanke M, Meyer C, Volzke H, Baumeister SE, Alte D. Tobacco smoking in relation to pain in a national general population survey. Prev Med. 2006;43:477-81. 
20. Kaila-Kangas L, Leino-Arjas P, Riihimaki H, Luukkonen R, Kirjonen J. Smoking and overweight as predictors of hospitalization for back disorders. Spine. 2003;28:1860-8.

21. Leboeuf-Yde C. Smoking and low back pain. A systematic literature review of 41 journal articles reporting 47 epidemiologic studies. Spine (Phila Pa 1976). 1999;24:1463-70.

22. Leclerc A, Gourmelen J, Chastang JF, Plouvier S, Niedhammer I, Lanoe $J$. Level of education and back pain in France: the role of demographic, lifestyle and physical work factors. Int Arch Occup Environ Health. 2009;82:643-52.

23. Lee SS, Kim SH, Nah SS, Lee JH, Lee YA, Hong SJ, et al. Smoking habits influence pain and functional and psychiatric features in fibromyalgia. Joint Bone Spine. 2011;78:259-65.

24. Mattila VM, Sahi T, Jormanainen V, Pihlajamaki H. Low back pain and its risk indicators: a survey of 7,040 Finnish male conscripts. Eur Spine J. 2008;17:64-9.

25. Oh TH, Hoskin TL, Luedtke CA, Weingarten TN, Vincent $A$, Kim $\mathrm{CH}_{\text {, et al. }}$ Predictors of clinical outcome in fibromyalgia after a brief interdisciplinary fibromyalgia treatment program: single center experience. PM R. 2012:4:257-63.

26. Palmer KT, Syddall H, Cooper C, Coggon D. Smoking and musculoskeletal disorders: findings from a British national survey. Ann Rheum Dis. 2003;62:33-6.

27. Pamuk ON, Donmez S, Cakir N. The frequency of smoking in fibromyalgia patients and its association with symptoms. Rheumatol Int. 2009;29:1311-4

28. Power C, Frank J, Hertzman C, Schierhout G, Li L. Predictors of low back pain onset in a prospective British study. Am J Public Health. 2001:91:1671-8.

29. Sarker MA, Rahman M, Harun-Or-Rashid M, Hossain S, Kasuya H, Sakamoto J, et al. Association of smoked and smokeless tobacco use with migraine: a hospital-based case-control study in Dhaka, Bangladesh. Tob Induc Dis. 2013;11:15.

30. Schmidt BL, Tambeli CH, Gear RW, Levine JD. Nicotine withdrawal hyperalgesia and opioid-mediated analgesia depend on nicotine receptors in nucleus accumbens. Neuroscience. 2001;106:129-36.

31. Scott SC, Goldberg MS, Mayo NE, Stock SR, Poitras B. The association between cigarette smoking and back pain in adults. Spine (Phila Pa 1976). 1999;24:1090-8.

32. Shiri R, Karppinen J, Leino-Arjas P, Solovieva S, Viikari-Juntura E. The association between smoking and low back pain: a meta-analysis. Am J Med. 2010;123:87. e7-35.

33. Simons CT, Cuellar JM, Moore JA, Pinkerton KE, Uyeminami D, Carstens MI, et al. Nicotinic receptor involvement in antinociception induced by exposure to cigarette smoke. Neurosci Lett. 2005;389:71-6.

34. Suh HW, Song DK, Lee KJ, Choi SR, Kim YH. Intrathecally injected nicotine enhances the antinociception induced by morphine but not beta-endorphin, D-Pen2,5-enkephalin and U50,488H administered intrathecally in the mouse. Neuropeptides. 1996;30:373-8.

35. Takeshima T, Ishizaki K, Fukuhara Y, ljiri T, Kusumi M, Wakutani Y, et al. Population-based door-to-door survey of migraine in Japan: the Daisen study. Headache. 2004;44:8-19.

36. Vogt MT, Hanscom B, Lauerman WC, Kang JD. Influence of smoking on the health status of spinal patients: the National Spine Network database. Spine (Phila Pa 1976). 2002;27:313-9.

37. Watkins EA, Wollan PC, Melton 3rd LJ, Yawn BP. A population in pain: report from the Olmsted County health study. Pain Med. 2008;9:166-74.

38. Weingarten TN, Moeschler SM, Ptaszynski AE, Hooten WM, Beebe TJ, Warner DO. An assessment of the association between smoking status, pain intensity, and functional interference in patients with chronic pain. Pain Physician. 2008;11:643-53.

39. Weingarten TN, Podduturu VR, Hooten WM, Thompson JM, Luedtke CA, Oh $\mathrm{TH}$. Impact of tobacco use in patients presenting to a multidisciplinary outpatient treatment program for fibromyalgia. Clin J Pain. 2009;25:39-43.

40. Yunus MB, Arslan S, Aldag JC. Relationship between fibromyalgia features and smoking. Scand J Rheumatol. 2002;31:301-5.

41. Zvolensky MJ, McMillan K, Gonzalez A, Asmundson GJ. Chronic pain and cigarette smoking and nicotine dependence among a representative sample of adults. Nicotine Tob Res. 2009;11:1407-14.

\section{Submit your next manuscript to BioMed Central and take full advantage of:}

- Convenient online submission

- Thorough peer review

- No space constraints or color figure charges

- Immediate publication on acceptance

- Inclusion in PubMed, CAS, Scopus and Google Scholar

- Research which is freely available for redistribution

Submit your manuscript at www.biomedcentral.com/submit 